\title{
INOVASI PRODUK BERBASIS DESAIN DIGITAL PADA TENUN KUBANG DI KABUPATEN LIMAPULUH KOTA
}

\section{INNOVATION OF DIGITAL DESIGN BASED PRODUCTS IN KUBANG WEAVING IN KABUPATEN LIMAPULUH KOTA}

\author{
${ }^{1)}$ Ratni Prima Lita*, ${ }^{2}$ Meuthia Meuthia, ${ }^{3)}$ Sari Surya ${ }^{4)}$ Devi Yulia Rahmi \\ ${ }^{1,2,3,4)}$ Program Studi Manajemen, Fakultas Ekonomi \\ Universitas Andalas \\ Kampus Limau Manih Padang \\ *Email: ratniprimalita@eb.unand.ac.id
}

\begin{abstract}
ABSTRAK
Tenun Kubang merupakan salah satu produk unggulan daerah Kabupaten Liampuluh Kota yang mempunyai keunikan motif. Motif masih dirancang secara manual, sehingga pengrajin membutuhkan waktu yang lama mendesain dan kesulitan berkreasi. Agar pengrajin lebih mudah mendesain motif maka dilakukan kegiatan pengembangan motif melalui desain digital. Mitra dari kegiatan ini adalah Tenun Kubang H.Ridwan By yang berlokasi di Kenagarian Kubang Kabupaten Limapuluh Kota. Tujuan dari kegiatan pengabdian adalah agar pengelola dan pengrajin Tenun Kubang mampu mendesain motif dan warna serta mendapatkan informasi tentang trend mode, dengan menggunakan corel draw dan fotoshop.. Metode yang digunakan adalah metode latihan, praktek dan konsultasi bisnis. Dengan kegiatan ini, mitra mampu mendesai motif secara digital, sehingga produk yang dihasilkan lebih menarik. Kegiatan pengabdian ini sangat penting dilakukan karena inovasi produk yang dilakukan melalui pengembangan motif berbasis digital membuat produk yang dihasilkan lebih diminati oleh konsumen dan meningkatnya variasi produk yang dihasilkan.
\end{abstract}

Kata Kunci: Desain; Digital; Tenun Kubang.

\begin{abstract}
Kubang Weaving is one of the superior products in the Limapuluh Kota Regency, which has a unique motif. Design of style still manually, so artisans need a long time to design and have difficulty creating. To more accessible, motive development activities carried out through digital design. The partner of this activity is Weaving Kubang H. Ridwan By, which is located in Kenagarian Kubang, Limapuluh Kota Regency. The purpose of the community service activities is that the managers and artisans of Kubang Weaving can design motifs and colours and obtain information about fashion trends, using coral draw and photoshop. The method used is the method of training, practice and business consultation. With this activity, partners can digitally design motifs, so the products produced are more attractive. This dedication activity is significant because product innovation carried out through the development of digital-based makes the products produced more appealing to consumers and the increasing variety of products produced.
\end{abstract}

Keywords: Design; Digital; Kubang Weaving.

Submited : 13 April $2020 \quad$ Revision : 07 Januari 2022 Accepted : 07 Januari 2022

\section{PENDAHULUAN}

Industri kreatif adalah sektor yang paling cepat pertumbuhannya dalam ekonomi global (Martinaityte \& Kregzdaite, 2015). Permintaan yang menurun dan ketatnya pembiayaan di tengah situasi penurunan ekonomi dunia menjadi tekanan bagi perusahaan-perusahaan besar dunia. Namun tak demikian dengan usaha kecil menengah (UKM) yang berbasis industri kreatif. Industri kreatif menjadi sektor paling tangguh untuk bertahan di tengah situasi krisis ekonomi global. Evolusi ekonomi kreatif mengacu pada rencana pengembangan ekonomi kreatif Indonesia tahun 2025. 
Laju pertumbuhan wirausahawan di Indonesia ikut mengalami peningkatan dengan munculnya industri kreatif, karena para pemula bisnis dengan modal terbatas dapat ikut menjalankan usaha hanya dengan modal kreatifitas. Pengusaha yang memiliki potensi untuk mengembangkan sektor ekonomi kreatif harus mampu mengembangkan inovasi produknya agar semakin bernilai tambah. Produk yang semakin meningkat nilai tambahnya berimbas pada peningkatan nilai jual produk tersebut pada pasar lokal, nasional maupun internasional. Selain itu, industri kerajinan perlu berorientasi pasar untuk mendorong kinerja organisasi lebih baik. Orientasi pasar membuat pelaku usaha mengetahui apa saja selera konsumen, peluang produk di pasar dan bagaimana suatu perusahaan meningkatkan nilai jual produknya dibanding pesaing, serta memperhatikan sumber daya dan pesaing. Orientasi pasar mendorong inovasi organisasi dan meningkatkan kinerja perusahaan (Lita, Meuthia, \& Faisal 2018). Hal ini juga sejalan dengan penelitian (Ramayah, Samat, \& Lo 2011; Altuntaş, Semerciöz, \& Eregez 2013, dan Hussain, Shah, \& Akhtar 2016) yang menyatakan adanya hubungan positif antara orientasi pasar dan kinerja organisasi. Orientasi pasar penting bagi organisasi dalam bersaing satu sama lain di pasar global, karena diperlukan baik dalam pemasaran maupun manajemen (Ramayah, Samat, \& Lo 2011).

Sumatera Barat (Sumbar) merupakan salah satu daerah yang memiliki potensi besar dalam bidang industri kreatif. Industri kerajinan bordir, sulaman dan tenun menjadi salah satu sub sektor usaha kriya yang banyak ditemukan di Sumbar. Beberapa daerah di Sumbar yang terkenal dengan kerajinan bordir, sulaman dan tenun tersebut berasal dari Pandai Sikek di Kabupaten Tanah Datar, Silungkang di Kabupaten Sawahlunto, Halaban dan Kubang di Kabupaten Lima Puluh Kota, Nareh di Kabupaten Padang Pariaman, Koto Gadang di Kabupaten Agam, Sumpur Kudus dan Sinyamu di Kabupaten Sijunjung. Masingmasing daerah menonjolkan keunikan pola dan corak motif yang berbeda-beda. Sebagai salah satu daerah pusat tenun tradisional yang masih berkembang saat ini, tenun Kubang menjadi salah satu produk primadona dalam penyelenggaraan pameran Inacraft di Jakarta pada bulan April 2016 lalu (Efita dalam lifetstyle.bisnis.com, 2016). Produk kerajinan tangan perlu melestarikan identitas budaya Minangkabau lokal. Inovasi produk melalui produk modifikasi seperti desain motif yang disesuaikan dengan fleksibilitas selera pasar sasaran bisa meningkatkan kinerja UKM (Lita \& Faisal 2018). Industri kerajinan mampu berdiri dan mengembangkan usahanya meskipun sebelumnya sempat nyaris punah. Bahkan saat ini pengrajin kewalahan memenuhi permintaan pelanggan. Hal ini disebabkan produksi masih sangat terbatas karena jumlah perajin yang ada sangat sedikit (Sumbartime.com, 2016).

Salah satu usaha tenun Minang adalah Tenun Kubang mengembangkan motif dengan adanya pelatihan-pelatihan dari pihak pemerintah daerah dan pusat. Begitu juga pemasarannya, tak lagi sebatas pasar tradisional. Namun sudah merambah pasar modern dan bekerjasama dengan designerdesigner local dan nasional (Sumbartime.com, 2016). Inovasi merupakan kunci sukses dalam pertumbuhan usaha yang terjadi. Inovasi produk berpengaruh terhadap pengembangan usaha berbasis desain digital. Realitanya pada bisnis kerajinan, inovasi produk memang memiliki pengaruh terhadap pertumbuhan usaha. Sehingga pemilik kerajinan harus mampu menciptakan inovasi pada produknya, terutama untuk mendapatkan orientasi laba yang ditargetkan. Jika didalam usaha kerajinan tidak dilakukan tindakan berupa inovasi, maka kemungkinan usaha akan mengalami penurunan.

Permasalahan yang dihadapi Tenun Kubang adalah rendah kreativitas motif dari produk tenun yang diproduksi pengrajin. Kemajuan teknologi diharapkan dapat menjadi katalisator untuk mengidentifikasi respon pasar terhadap kualitas, warna, bahan, dan desain/ corak motif sehingga produk mampu bersaing tidak hanya di skala lokal, nasional, namun juga global. Desain warna yang masih kesulitan dipadupadankan, pemanfaatan teknologi untuk desain belum optimal. 
Diferensiasi produk dari pesaing belum optimal disebabkan kemampuan desain masih rendah. Selain itu, belum adanya produk pakaian dan soevenir yang bisa dijual ke wisatawan dan pemanfaatan limbah sebagai souvenir. Tenun Kubang merupakan salah satu pusat penghasil kerajinan tenun Minang yang merupakan produk unggulan daerah Kabupaten Limapuluh Kota. Produksi diolah dengan menggunakan mesin tenun ATBM (Alat Tenun Bukan Mesin) dengan kapasitas produksi berkisar 180 helai sampai 200 helai perbulannya dengan anggota pekerja lebih kurang 25 orang pekerja tenun. Sumber daya manusia masih terbatas mendapatkan informasi tentang trend mode dan kemampuan desain dengan digital masih terbatas. Pengerjan desain motif yang lama, model yang cenderung monoton dan warna yang kurang menarik menjadi permasalahan pada Tenun Kubang. Produk dirancang dengan motif dan warna tertentu, masih kurang mengikuti trend mode. Belum ada usaha memanfaatkan teknologi untuk mencari trend mode atau keinginan konsumen.

Kondisi Tenun Kubang ini sesuai dengan hasil kegiatan penelitian Lita et al. (2017) di Sumbar, dimana masih ditemukan pada UMKM yaitu inovasi produk yang masih terbatas sehingga desain yang masih terbatas. Kegiatan pengabdian Lita, Yeni \& Syahrul (2016), dan pada usaha kerajinan termasuk tenun Kubang mempunyai potensi pasar yang bagus baik lokal, nasional maupun internasional, namun masih banyak permasalahan pada aspek bisnis usaha mulai dari bahan baku, produksi, proses, produksi, manajemen usaha, sumber daya manusia,pemasaran, fasilitas dan finansial. Penelitian Lita et al. (2017) juga menemukan inovasi organisasi mempengaruhi kinerja usaha kecil. Selain itu, perlu juga mengembangkan UKM berbasis teknologi informasi baik untuk produksi, pemasaran maupun keuangan. Padahal, pemanfaatan teknologi dan sistem informasi dalam menjalankan industri kreatif dapat menjadi modal daya saing usaha tersebut untuk terus berkembang. Menurut (Laužikas \& Mokšeckienė 2014), teknologi informasi menyebabkan perkembangan dan penyebaran industri kreatif, yaitu untuk menjangkau daerah geografis yang jauh karena efisiensi komunikasi dengan negara lain serta peluang pemasaran yang lebih luas.

Untuk itu usaha kerajinan Tenun Kubang perlu melakukan pengembangan inovasi produk berbasis desain digital seperti membuat katalog produk (softcopy dan virtual) dan pembenahan dari sistem informasi penjualan. Harapannya desain digital mampu meningkatkan nilai seni dan keunikan produk tenun untuk pasar sasaran yang lebih luas. Dari latar belakang dan analisis situasi yang dilakukan pada usaha kerajinan Minang tenun Kubang, maka dilakukanlah kegiatan pengabdian tentang "Inovasi Produk Berbasis Desain Digital pada Tenun Kubang Khas Minang di Kabupaten Limapuluh Kota"

Tujuan kegiatan pengabdian ini adalah: 1) melatih pengusaha dan pengrajin mendesain motif secara digital, sehingga bisa meningkatkan inovasi produk tenun Kubang, dan 2) mendampingi pengelola dan pengrajin merancang produk yang inovatif dengan desain digital, sehingga mengikuti trend mode. Pengusaha lebih beorientasi kepada keinginan konsumen (pasar). Perusahaan yang beorientasi konsumen akan mampu meningkatkan inovasi perusahaan. Hal ini sesuai dengan hasil penelitian Lita et al. (2018) dimana orientasi pasar mampu meningkatkan inovasi organisasi. Selain itu, orientasi mampu meningkatkan kinerja perusahaan. Penelitian ini juga didukung oleh penelitian Ramayah, Samat, \& Lo (2011) dan Hussain, Shah, \& Akhtar (2016) yang menyatakan adanya hubungan positif antara orientasi pasar dan kinerja organisasi.

Usaha tenun Kubang yang memperhatikan motif yang lebih beorientasi pasar akan bisa meraih keunggulan kompetitif dan mampu bersaing dengan menggunakan sumber daya yang dimilikinya. Hal ini sesuai dengan hasil penelitian Choi (2014) dimana upaya organisasi untuk menciptakan dan mempertahankan keunggulan kompetitif melalui respon sensitif terhadap perubahan pasar di bawah nilai superior untuk pelanggan, 
dengan memperhatikan orientasi pelanggan, sumber daya orientasi, dan orientasi pesaing. Lebih lanjut Liao et al. (2011) menyatakan bahwa ketika orientasi pasar organisasi menghasilkan nilai bagi pelanggan yang langka dan sulit tirukan, itu menjadi sumber keunggulan kompetitif yang berkelanjutan.

Dengan kegiatan pengabdian yang telah dilakukan diharapkan mitra mampu meningkatkan daya saing produknya di pasar dan mampu meningkatkan daya saingnya. Jika usah tenun Kubang mampu bersaing di pasar, secara tidak langsung akan meningkatkan kinerja pemasarannya dan akhirnya mampu meningkatkan kinerja persahaannya.

\section{METODE}

Kegiatan pengabdian dilaksanakan dalam tiga tahapan yaitu:

1. Persiapan Kegiatan

Dalam tahap persiapan dilaksanakan 3 kegiatan yaitu:

a. Sosialisasi dan pengurusan ijin dengan pihak institusi terkait.

b. Mengontak pengusaha untuk memutuskan jadwal kegiatan.

c. Menyusun modul pelatihan.

d. Mempersiapkan pelaksanaan kegiatan.

2. Pelaksanaan Kegiatan

Metode kegiatan yang digunakan untuk menyelesaikan permasalahan yang dihadapi pengrajin dan pengusaha adalah metode pelatihan, konsultasi dan praktek .

3. Monitoring dan Evaluasi Kegiatan

Kegiatan yang telah dilakukan diadakan kegiatan monitoring dan evaluasi sebagai berikut:

a. Evaluasi pelaksanaan kegiatan, dengan membandingkan hasil pre test dengan post test, jumlah desain dan produk yang dihasilkan.

b. Monitoring pelaksanaan kegiatan

c. Laporan pelaksanaan kegiatan

\section{HASIL DAN PEMBAHASAN}

Lokasi usaha yang dibina berada lebih kurang $129 \mathrm{~km}$ dari Universitas Andalas (Padang) dan lebih kurang $15 \mathrm{~km}$ dari pusat Kota Payakumbuh. Lokasi bisa dicapai dengan kendaraan roda dua dan empat. Jalur lokasi usaha bisa diakses dengan angkutan umum. Kegiatan ini melibatkan 1 orang pengelola dan pimpinan dan 2 orang karyawan/pengarajin. Kegiatan pengabdian ini melibatkan 3 orang personil yang terdiri dari seorang koordinator pelaksana dan dua orang anggota pelaksana kegiatan yang memiliki kepakaran dalam desain.

Kegiatan yang telah dilaksanakan dimulai dengan koordinasi awal tim membicarakan persiapan kegiatan, penyusunan modul dan luaran kegiatan yang ingin dicapai. Kegiatan ini menghasilkan rencana kegiatan yang akan dilaksanakan. Selanjutnya dilakukan sosialisasi dan pengurusan ijin kegiatan dari instansi terkait.

Pelaksanaan kegiatan dimulai dengan pengembangan desain motif tenun berbasis digital dengan corel draw dan fotoshop. Mitra akhirnya mampu mendesain produk lebih cepat yaitu dari 1 motif seminggu menjadi 1-2 motif sehari. Hal ini berdampak terhadap produksi tenun setiap bulannya. Selain itu, usaha tenun Kubang mempunyai produk yang lebih banyak dengan bahan bagus untuk kalangan segmen atas, yakni sekitar 20\% produk yang ditawarkan adalah dengan bahan yang bagus. Produk yang dihasilkan mempunyai diffensiasi produk yang mampu membedakannya dengan produk pesaing, ada sekitar 20\% produk telah terdiffrensiasi.

Tenun Kubang mampu mendesain motif dan warna serta mendapatkan informasi tentang trend mode, dimana adanya 1 orang SDM yang mampu memahami dan mengaplikasikan trend mode. Selain itu, telah dilakukan dasar-dasar desain motif berbasis digital membuat mereka telah memahami dan mengaplikasikan desain dengan menggunakan corel draw dan fotoshop. Inovasi produk yang dilakukan melalui pengembangan motif berbasis digital membuat produk yang dihasilkan lebih diminati oleh konsumen. Konsumen menilai desain tenun lebih bervariasi dan tidak terpaku pada motif lama saja (dikenal dengan motif Rangkiang).

Dengan adanya produk baru dari desain yang inovatif mampu meningkatkan pendapatan usaha tenun Kubang dan 
menambah variasi produk yang dijual juga bertambah. Selain itu desain motif yang telah dibuat didaftarkan HAKI dan saat ini sudah ada 2 desain yang memperoleh sertifikat.

Mitra cukup berperan aktif dalam kegiatan ini. Hal ini dapat dilihat dari tahap persiapan dana sampai kegiatan ini dilaksanakan. Mereka sangat antusias dan berminat untuk terus meningkatkan usaha mereka dengan pengembangan motif. Dalam kegiatan ini, mitra berperan dalam menentukan jadwal kegiatan dan aktif dalam pelatihan, diskusi, praktek dan konsultasi bisnis.

\section{UCAPAN TERIMA KASIH}

Terima kasih diucapkan kepada Direktorat Riset dan Pengabdian Masyarakat Deputi Bidang Penguatan Riset dan Pengembangan Kementerian Riset dan Teknologi/ Badan Riset dan Inovasi Nasional sesuai dengan Kontrak Pelaksanaan Program Pengabdian Masyarakat Nomor:

047/SP2H/PPM/DRPM/2020, tanggal 16 Maret 2020 Tahun Anggaran 2020.

\section{SIMPULAN}

Kegiatan pengabdian telah meningkatkan kemampuan pengelola dan pengrajin Tenun Kubang dalam mendesain motif dan warna serta mendapatkan informasi tentang trend mode, dengan menggunakan corel draw dan fotoshop. Metode yang digunakan adalah metode latihan, praktek dan konsultasi bisnis. Dengan kegiatan ini, mitra mampu mendesai motif secara digital, sehingga produk yang dihasilkan lebih menarik. Kegiatan pengabdian ini sangat penting dilakukan karena inovasi produk yang dilakukan melalui pengembangan motif berbasis digital membuat produk yang dihasilkan lebih diminati oleh konsumen dan meningkatnya variasi produk yang dihasilkan. Kegiatan yang berkelanjutan sangat diperlukan agar kemampuan berinovasi dari mitra terus meningkat.

\section{DAFTAR PUSTAKA}

Altuntaş, Gültekin, Fatih Semerciöz, \& Hanife Eregez. (2013). Linking Strategic and
Market Orientations to Organizational Performance: The Role of Innovation in Private Healthcare Organizations. Procedia-Social and Behavioral Sciences 99: 413-19.

Choi, S. (2014). Learning orientation and market orientation as catalysts for innovation in nonprofit organizations. Nonprofit and Voluntary Sector Quarterly, 43(2), 393-413.

Hussain, Jawad, Fayaz Ali Shah, \& Ch Shoaib Akhtar. (2016). Market Orientation and Organizational Performance in Small and Medium Sized Enterprises. A Conceptual Approach. City University Journal 6(1): 166-80.

Laužikas, Mindaugas, \& Rasa Mokšeckienè. (2014). The Development of Creative Industries: The Case of Lithuanian Fashion Design Companies.

Lifestyle. (2016). Inacraft 2016: Tenun Kubang Jadi Salah Satu Produk Primadona di Gerai Sumatera Barat, tersedia di: http://lifestyle.bisnis.com/read/20160421/ 104/540223/inacraft-2016-tenun-kubangjadi-produk-primadona-di-geraisumatera-barat (Diakses pada 28 Juli 2018).

Lita, Ratni Prima, Yeni, YH., \& Syahrul L. (2016). Program pelatihan dan konsultasi Bisnis tentang Produksi Bersih dan Laporan Keunagan pada Usaha "Istana Rendang" di Kanagarian Mungka Kabupaten Lima Puluh Kota. Jurnal Warta Pengabdian Andalas (23) 3.

Lita, Ratni Prima, Meuthia, \& Ranny Fitriana Faisal. (2017) Pengembangan Model Implementasi Inovasi Usaha Berbasis Market Orientation, Entrepreneurial Orientation, Leadership, dan Culture pada Industri Kreatif. IN Patent. 02 (498)

Lita, Ratni Prima, \& Ranny Fitriana Faisal. (2018). SME's performance of creative industries supporting tourism in indonesia: market orientation, learning 
orientation and organizational innovativeness as determinants. Academy of Marketing Studies Journal 22 (1).

Lita, Ratni Prima, Meuthia Meuthia, \& Ranny Fitriana Faisal. (2018). Model Keterkaitan Market Orientation, Leadership, Organizational Innovation Dan Organizational Performance Pada Industri Kerajinan Di Sumatera Barat. Jurnal Siasat Bisnis 22(1): 38-61.

Luo, X., Zhou, L., \& Liu, S. S. (2005). Entrepreneurial firms in the context of China's transition economy: an integrative framework and empirical examination. Journal of Business Research, 58(3), 277-284.

Martinaityte, Eugenija, \& Rusne Kregzdaite. (2015). The Factors of Creative Industries Development in Nowadays Stage. Economics \& Sociology 8(1): 55.

Merdeka. 2017, Industri Kreatif Sumbang 7,38 Persen Terhadap PDB Nasional", tersedia di: https://www.merdeka.com/uang/industrikreatif-sumbang-738-persen-terhadappdb-nasional.html (Diakses pada 29 Juli 2018)

Ramayah, T, Nusrah Samat, \& May-Chiun Lo. (2011). Market Orientation, Service Quality and Organizational Performance in Service Organizations in Malaysia. Asia-Pacific Journal of Business Administration 3(1): 8-27.

Sumbartime. (2016). Pengrajin Tenun Makin Langka, Monalisa Irfendi Ajak Generasi Minati Songket Kubang", tersedia di: http://sumbartime.com./pengrajin-tenunmakin-langka-monalisa-irfendi-ajakgenerasi-minati-songket-kubang/ (Diakses pada 28 Juli 2018). 